Trivent Publishing

(C) The Authors, 2016

Available online at http://trivent-publishing.eu/

Engineering and Industry Series

Volume Power Systems, Energy Markets and Renewable Energy Sources in

South-Eastern Europe

\title{
Designing Grid Protections to Accommodate Distributed Generation
}

\author{
Papastefanakis Dimitrios, ${ }^{1}$ Orfanoudakis George, ${ }^{1}$ \\ Siderakis Kiriakos ${ }^{2}$ \\ ${ }^{1}$ Department of Electrical Engineering, Technological Educational Institute of Crete, \\ Greece, dipapastefan@gmail.com \\ ${ }^{2}$ Hellenic Electricity Distribution Network Operator S.A (HEDNO), Greece
}

\begin{abstract}
The operation of electric power systems has considerably changed after the integration of renewable energy sources in transmission and distribution networks. Considering fault conditions, the fault current can now be supplied from both the centralized power plants and the distributed energy sources. Currently, a "rule of thumb" used by the industry, is that inverter-based DG systems contribute two times their rated current to the amount of the fault current. This study aims at further investigation of the fault current contribution of $P V$ systems under different fault conditions, with the aim of providing guidelines for setting the thresholds of the grid protections. An example of lowvoltage grid section and PV inverter are simulated in MATLAB-Simulink. The results illustrate that in parts of the grid where $P V$ systems are connected, protection levels may have to be reduced to appropriately react to highimpedance phase to ground faults.
\end{abstract}

This is an Open Access article distributed in accordance with the Creative Commons Attribution Non Commercial (CC-BY-NC-ND 4.0) license, which permits others to copy or share the article, provided original work is properly cited and that this is not done for commercial purposes. Users may not remix, transform, or build upon the material and may not distribute the modified material (http://creativecommons.org/licenses/by-nc/4.0/) 


\section{Keywords}

Protection systems; distributed generation (DG); photovoltaics (PV); PV inverters; fault current; high impedance faults (HIF);

\section{Introduction}

The design of protection systems plays a key role during the planning and operation of an electrical power system. Protection systems aim at detection and removal of faults. In electrical power systems, faults can be short circuits or overloads. Ground faults are the most common faults in industrial and commercial power systems. Even though high impedance in the fault path may reduce the fault current magnitude, ground faults can be destructive. During the planning of protection systems, a discrete fault level is assigned to every point of the distribution network to represent the maximum fault current expected to appear at that point. The available fault current determines the selection of relays, fuses and other over-current protection devices (Industry Applications Society December 2001).

\section{Factors that affect the fault current level}

The presence of DG in modern distribution networks constitutes an additional complexity with respect to the calculation of fault levels (Kiriakos Siderakis, Antiopi Gigantidou, Konstantinos Lagouvardos, Eleftheria Kavousanaki 2015). The fault current contribution from DG is affected by a number of factors (CIGRE WG C6.24 2014):

\section{A. The type of $D G$}

Synchronous or asynchronous generators directly connected to the grid will contribute higher fault current than the DG with a power electronic interface. The most commonly used power electronic converters for DG applications are voltage source inverters (VSIs). Inverters do not present the same dynamic behavior as synchronous or induction machines mainly because they lack mechanical and inductive characteristics (J. Keller and Kroposki). Moreover, grid-connected inverters are normally programmed to perform current control, as well as to respond within given time limits to different fault conditions. 


\section{B. The type of fault}

A "rule of thumb" currently used by the industry, is that inverter-based DG contributes approximately 2 times its rated current to the amount of fault current. This has been supported by a number of studies based on experimental results on commercial grid-connected inverters. Nevertheless, this fault current level only refers to phase-to-ground (zero impedance) faults of single-phase inverters (SMA Solar Technology AG), (Jamie Keller et al.) and three-phase short circuit (SC) faults of three-phase inverters (SMA Solar Technology AG), (G. Ball, B. Brooks, J. Flicker, J. Johnson, A. Rosenthal, J. 2013), (Farid Katiraei, Juergen Holbach, Tim Chang, Wesley Johnson, David Wills, Bing Young, Luis Marti, Andrew Yan, Peter Baroutis, Gary Thompson, Janos Rajda).

\section{Transformer presence and configuration}

The presence of a transformer between the contributing DG and the fault can affect the fault current in the case of two or three-phase SCs, since the fault current may be limited by transformer short circuit impedance. Moreover, the transformer configuration (Delta / Wye / Grounded Wye at primary/secondary) plays a definitive role in the case of ground faults. Namely, if the grid-side winding of the transformer is connected in Delta or non-grounded Wye, the DG does not contribute any current to the ground fault, since there is no path for current to flow between the DG and the ground. In the case of multiple transformers, for example in wind power plants, the transformer of each individual wind turbine can have a grounded Wye secondary (grid-side), but the effect will be the same if the substation transformer secondary is in Delta or nongrounded Wye (V. Gevorgian and E. Muljadi).

\section{Network synthesis and distance from fault}

The synthesis of the network, i.e. the installed equipment between the DG and the fault, will also affect the fault current contribution from the DG. Moreover, the distance of the DG from the fault, which increases the equivalent cable impedance, will reduce the fault current.

\section{Photovoltaic systems}

With regards to the power system of Crete, PV generation is the most common technology of DG, both in $20 \mathrm{kV}$ and $400 \mathrm{~V}$ networks. The present study will therefore focus on the effect of connecting photovoltaic (PV) systems to the grid protections. Studies referring to Wind power plant fault current contribution can 
be found in (V. Gevorgian and E. Muljadi), (Valentini June 2008), (Muljadi et al.), (Joakim Ahnlund 2014), (IEEE Power and Energy Society, Joint Working Group 2014). The aim of this paper is:

a) to quantify the fault current contribution from PV inverters under different fault conditions,

b) to evaluate the fault behaviour of distribution networks and protection systems in the presence of PV inverters, and

c) to provide guidelines for sizing and configuring these systems, to properly handle the modified fault characteristics.

\section{A. Fault current contribution from PV inverters}

With reference to the factors affecting the fault current levels, listed in the Section 2, the following can be noted for the case of PV systems:

1. Type of DG: PV systems are connected to the grid via currentcontrolled single- or three-phase inverters. They do not have rotating mechanical parts (with high rotational inertia) or inductive characteristics, thus the power supplied to the grid is entirely controlled by the inverter.

2. Type of fault: For single-phase inverters, a ground fault (assuming the grid neutral is grounded) will cause a transient current of $\sim 2$ times the inverter nominal current (J. Keller and Kroposki), followed by the inverter disconnection from the grid (due to low inverter terminal voltage. A threephase SC at the output of a three-phase inverter will have a similar result (G. Ball, B. Brooks, J. Flicker, J. Johnson, A. Rosenthal, J. 2013), (Farid Katiraei, Juergen Holbach, Tim Chang, Wesley Johnson, David Wills, Bing Young, Luis Marti, Andrew Yan, Peter Baroutis, Gary Thompson, Janos Rajda). A ground fault in the case of a three-phase inverter, on the other hand, is a very different condition, on which this paper will focus.

3. Transformer: For the case of single-phase inverters, the presence of a transformer is expected to have minor effect on the behaviour during a ground fault. The inverter, transformerless or not, will disconnect from the grid within a fraction of a second, as dictated by the relevant standards (IEEE Standards Coordinating Committee 21 April 2009). The same holds for three-phase inverters, for the case of SC faults. However, as mentioned above, a ground fault in the case of three-phase inverters is a different condition: Three-phase PV inverters are either transformerless, or they are connected to the grid using a Wye - Delta (grid side) transformer. In both cases (see Section 2.3), there is no path for current to flow between the DG and the ground, thus the inverter cannot contribute to fault current.

4. Network synthesis: Will be considered in Section 5 of this study. 


\section{B. Effect on grid protection systems}

Based on the discussion in previous section, the following can be concluded:

- Transient fault current contribution, with a duration in the order of 10's of $\mathrm{ms}$, can be $\sim 2$ times the inverter nominal current. This applies to singlephase inverter ground faults and three-phase inverter SCs or phase-tophase faults. The fault will be detected by the inverter, which will disconnect from the grid. Moreover, the fault current contribution of the grid can be in the order of kA's, since, unlike the inverter current, the grid current is not a controlled quantity. For low-power inverters, i.e. inverters with current output in the order of 10's of A, this can practically mean that the inverter fault current contribution can be neglected

- In the case of ground faults for 3-phase inverters, there is no transient fault current contribution by the inverter, since for typical transformer configurations there is no path for current to flow between the inverter and the ground. Depending on the voltage change (phase-phase, phaseground) at the inverter terminals when the fault occurs, the inverter may continue to operate normally. In the following sections, this study will investigate a case of High Impedance Fault (HIF), where the existence of a three-phase PV inverter affects the response of the grid protections (fuses) to the fault.

Initially, the effects of a fault at the LV feeder and at the Point of Common Coupling (PCC) will be investigated, assuming that the inverter is not connected. Subsequently, the inverter is connected and the same quantities are measured again and compared with the results of the first case. Results are presented and discussed, focusing on the implications on the grid's protections.

\section{High impedance faults}

The faults on distribution feeders with faults currents below traditional overcurrent protection (fuses and overcurrent relays) pickups are known as High-Impedance Faults (HIF). The main causes of HIF may be fallen conductors on poorly conductive surfaces or tree branches brushing power lines. HIFs generally do not affect power system operation because they have such small fault currents. However, they are dangerous for public safety, especially those which are caused by downed power lines. Thus, the detection of HIF has been a subject of intense interest over the history of electric utility systems (Hou), (Sedighizadeh M., Rezazadeh A., and Elkalashy N. 2010). 


\section{System model}

The following study is performed through simulations in MATLAB-Simulink. This section presents the parameters and assumptions adopted to model each part of the system.

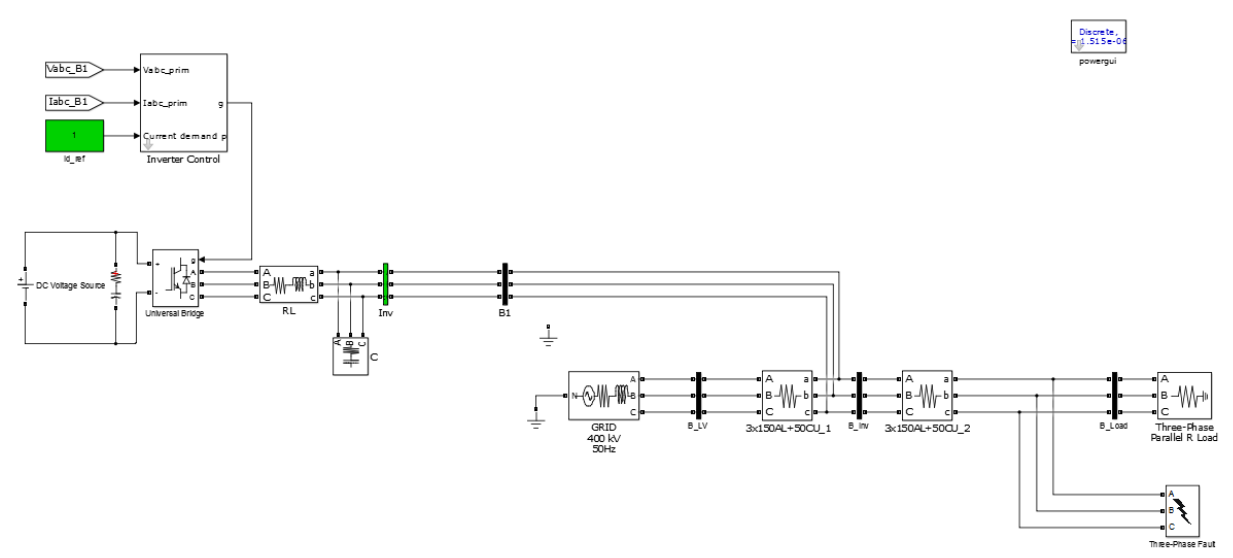

Fig. 1.System model in Simulink

\section{A. Grid model}

The Simulink model of the system is illustrated in Fig.1. The grid is simulated based on real data for the MV-LV feeders and the MV/LV transformer. Moreover, the grid's fuses are simulated considering their actual rating and response times.

The equivalent circuit of the grid is calculated in accordance with IEC 60909 (Kasikci 2002), assuming that the 3-phase short-circuit level at the point of the $\mathrm{HV} / \mathrm{MV}$ transformer is $250 \mathrm{MVA}$. A $2 \mathrm{~km} \mathrm{MV}$ feeder (ACSR 95) is assumed to be connected to a $630 \mathrm{kVA} \mathrm{MV} / \mathrm{LV}$ transformer. The $\mathrm{LV}$ feeder is assumed to be $3 \mathrm{X} 150 \mathrm{AL}+50 \mathrm{CU}$ and be protected by a $500 \mathrm{~A}$ fuse.

Finally, the grid is simulated as a three-phase voltage source presenting the following characteristics:

Table 1. Grid simulation parameters.

\begin{tabular}{|c|c|}
\hline Parameter & Value \\
\hline Phase-to-phase voltage (Rms) & $400 \mathrm{~V}$ \\
\hline Frequency & $50 \mathrm{~Hz}$ \\
\hline 3-phase short-circuit level & $16.25 \mathrm{MVA}$ \\
\hline X/R ratio & 10 \\
\hline
\end{tabular}




\section{B. PV inverter model}

The inverter is assumed to have a power rating of $85 \mathrm{~kW}$, representing an equivalent of five $17 \mathrm{~kW} 3$-phase PV inverters. Such inverters are typical in PV stations on Crete. The inverter controller model includes:

- A 3-phase PLL, capable of operating with imbalanced grid voltages, which appear during fault conditions (Yazdani and Iravani 2010).

- A synchronous (dq) reference frame current controller, with d-q component decoupling and grid voltage feed-forward (Yazdani and Iravani 2010).

- A number of protections typically implemented in PV inverters. The inverter protection levels and corresponding time limits are set according to the IEEE 1547 international standard (IEEE Standards Coordinating Committee 21 April 2009).

Note that the MPPT and dc-link voltage (i.e. reference output current) controller are not part of the PV inverter model, since the PV array output power and hence the inverter reference output current (Id,ref) are assumed to be constant in the context of analysing a fault.

\section{Load model}

The load is assumed to be a balanced $300 \mathrm{~kW}$ linear load, representing a group of ideal consumers.

\section{Fault model}

The study focused on single phase to ground faults. To represent a HIF, the fault resistance was given a value of $1 \Omega$.

\section{Simulation results}

At first, the inverter is assumed not to be connected to the grid. The load current, totally supplied by the grid in this case, is $416 \mathrm{~A}$. According to the simulation results, when the fault occurs, a fault current to ground of approximately $209 \mathrm{~A}$ will appear. The grid then energizes the feeder through the faulty phase with a current of $616 \mathrm{~A}$. The assumed $500 \mathrm{~A}$ fuse, which protects the feeder, will then melt within a number of hours, according to typical time/current characteristic curve of a fuse link of $\mathrm{gL}$ operational class.

The system is subsequently simulated again, with the inverter connected. The load current in this case is shared between the inverter and the grid. Namely, the inverter supplies 124 A to the load, while the grid supplies the remaining $296 \mathrm{~A}$. When the fault occurs, the inverter does not contribute any current to the fault, as expected based on the discussion in Section 3. The grid provides almost the same fault current as before, that is 211 instead of 209 A. However, what is important w.r.t. the grid's protection is that the grid now energizes the feeder 
with a current of $498 \mathrm{~A}$. The $500 \mathrm{~A}$ fuse, will therefore not melt in this case and the grid will continue to operate. The results in both cases are presented in Table 2 .

Table 2. Simulation results.

\begin{tabular}{|c|c|c|}
\hline \multirow{2}{*}{ Parameter } & \multicolumn{2}{|c|}{ Value (Rms) } \\
\cline { 2 - 3 } & $\begin{array}{c}\text { No inverter } \\
\text { connected }\end{array}$ & $\begin{array}{c}\mathbf{8 5} \boldsymbol{k W} \text { inverter } \\
\text { connected }\end{array}$ \\
\hline $\mathrm{V}_{\text {load,ab }}$ & $379 \mathrm{~V}$ & $398 \mathrm{~V}$ \\
\hline $\mathrm{I}_{\text {load,a }}$ & $407 \mathrm{~A}$ & $412 \mathrm{~A}$ \\
\hline $\mathrm{V}_{\text {grid,ab }}$ & $398 \mathrm{~V}$ & $398 \mathrm{~V}$ \\
\hline $\mathrm{I}_{\text {grid,a }}$ & $616 \mathrm{~A}$ & $498 \mathrm{~A}$ \\
\hline $\mathrm{I}_{\text {fault,a }}$ & $209 \mathrm{~A}$ & $211 \mathrm{~A}$ \\
\hline
\end{tabular}

Fig. 2 illustrates the reaction of the inverter to the phase-to-ground fault. It can be seen that the output currents practically remain unchanged after the occurrence of the fault (at $\mathrm{t}=0.25 \mathrm{~s}$ ). The $85 \mathrm{~kW}$ inverter provides $124 \mathrm{~A}$, which is its nominal output current, both before and after the fault. This happens because the inverter adjusts its voltage references to keep its output current constant. Moreover, the phase-to-phase voltages seen by the inverter during the fault are not significantly low or imbalanced ( [Vab Vbc Vca] $=\left[\begin{array}{lll}398 & 399 & 400\end{array}\right]$ V). According to IEEE 1547 standard, the protection function of the inverter will therefore not react, and the inverter will continue to operate in parallel with grid and energize the load (IEEE Standards Coordinating Committee 21 April 2009). 


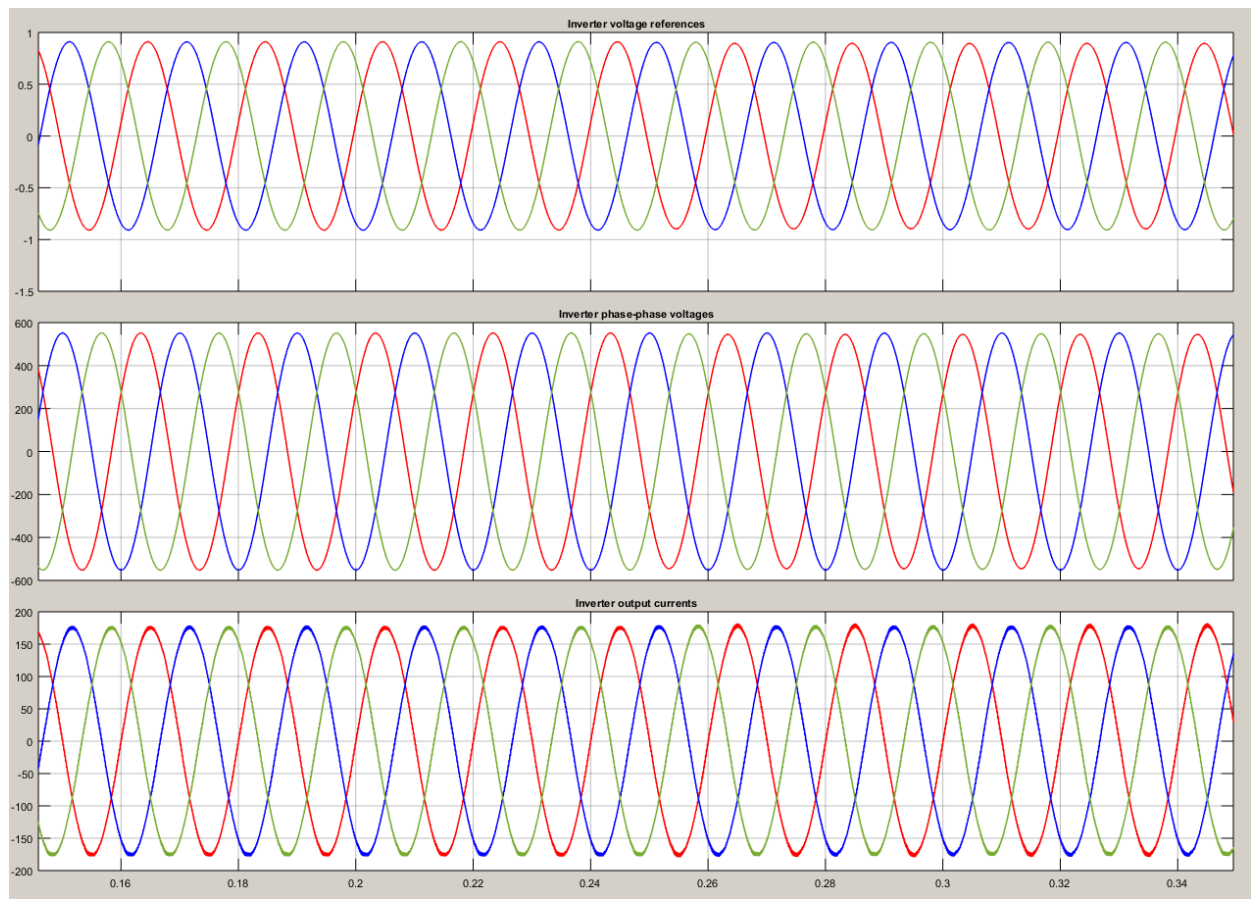

Fig. 2. Inverter waveforms a) Voltage reference b) Phase-to-phase voltages c) Output currents. Fault occurring at $t=0.25 \mathrm{~s}$.

\section{Guidelines}

The connection of the inverter to the system therefore affects the grid protection in the presented case in an indirect way: The inverter does not affect the fault current, but it decreases the current supplied by the grid to the load under normal and HIF operation. Since the total current for the faulty phase is the (vectorial) sum of the two (load and fault) currents, its value is lower when the inverter is connected to the system. This leads to the grid fuse not melting, whereas it would melt if the inverter was not connected to the system.

A suggestion based on the above observation would therefore be to select the grid protections taking into account the current supplied by connected PV inverters under normal operation. That is, for example, if at a given LV feeder, PV inverters cover the $20 \%$ of the load power, the grid protection levels could be set lower by the same percentage. On the other hand, the power generation from renewable sources is not constant, thus this setting could prove too sensitive for periods when this power is low. Ideally, the grid protections would have to be aware of the instantaneous $\mathrm{PV}$ power production 
on the respective feeder, and adjust their thresholds accordingly. Low voltage distribution networks do not currently have the appropriate equipment for full observation of the grid feeders. Therefore, further

research needs to be done for the development of adaptive protection schemes, based on advanced communication infrastructures (Martin Geidl), (Ogden and Yang).

\section{Conclusions}

This study investigated the effect that the connection of PV generators can have on the grid's protections. It was shown that, apart from transient effects, the nominal (i.e. not during faults) current contribution of three-phase PV inverters should be considered when determining the protection levels of low voltage feeders. This was demonstrated through a case of a phase to ground fault with high impendence to ground.

The detection of high impedance faults on electrical distribution systems has been one of the most persistent and difficult problems faced by the electric utility industry, and the integration of DG is making it more difficult. The implementation of adaptive protections is a demanding task, but crucial for the future of power grids and the development of Smart grids.

\section{References}

CIGRE WG C6.24. 2014. "Capacity of Distribution Feeders for Hosting DER.”. Farid Katiraei, Juergen Holbach, Tim Chang, Wesley Johnson, David Wills,

Bing Young, Luis Marti, Andrew Yan, Peter Baroutis, Gary Thompson, Janos Rajda. "Investigation of Solar PV Inverters Current Contributions during Faults on Distribution and Transmission Systems Interruption Capacity." Quanta Technology. http://quantatechnology.com/sites/default/files/docfiles/Solar\%20PV\%20Inverter\%20formatted.pdf.

G. Ball, B. Brooks, J. Flicker, J. Johnson, A. Rosenthal, J. 2013. "Inverter ground-fault detection 'blind spot' and mitigation methods." Solar America Board for Codes and Standards.

http://www.solarabcs.org/about/publications/reports/blindspot/pdfs/inverter_ groundfault-2013.pdf.

Hou, Daqing. "Detection of high-impedance faults in power distribution systems." In 2007 Power Systems Conference: Advanced Metering, Protection, Control, Communication, and Distributed Resources, 85-95.

IEEE Power and Energy Society, Joint Working Group, ed. 2014. Fault current contributions from wind plants.

IEEE Standards Coordinating Committee 21. 2009. IEEE Application Guide for IEEE Std 1547, IEEE Standard for Interconnecting Distributed Resources with Electric Power Systems, no. IEEE Std 1547.2-2008. 
Industry Applications Society. 2001. IEEE recommended practice for protection and coordination of industrial and commerical power systems. IEEE standard, no. IEEE Std 242-2001. New York, NY: Inst. of Electrical and Electronics Engineers.

Joakim Ahnlund. 2014. "Short-circuit Contributions from Fully-rated Converter Wind Turbines." Master's Thesis at EES, KTH Royal Institute of Technology.

Kasikci, Ismail. 2002. Short circuits in power systems: A practical guide to IEC 60 909: Wiley-VCH.

Keller, J., and B. Kroposki. "Understanding Fault Characteristics of InverterBased Distributed Energy Resources.” NREL. doi:10.2172/971441.

Keller, Jamie, Benjamin Kroposki, Richard Bravo, and Steven Robles. "Fault current contribution from single-phase PV inverters." In 2011 37th IEEE Photovoltaic Specialists Conference (PVSC), 1822-26.

Kiriakos Siderakis, Antiopi Gigantidou, Konstantinos Lagouvardos, Eleftheria Kavousanaki. 2015. "Fleet Management and Grid Integration of PV Generating Stations." Deregulated Electricity Market Issues in South Eastern Europe 1. doi:10.1002/9781119197249.ch1.

Martin Geidl. "Protection of Power Systems with Distributed Generation: State of the Art." Swiss Federal Institute of Technology (ETH) Zurich. http://ecollection.library.ethz.ch/eserv/eth\%3A27990/eth-27990-01.pdf.

Muljadi, E., N. Samaan, V. Gevorgian, Jun Li, and S. Pasupulati. "Short circuit current contribution for different wind turbine generator types." NREL. http://www.nrel.gov/docs/fy10osti/47193.pdf.

Ogden, Richard, and Jin Yang. "Impacts of distributed generation on lowvoltage distribution network protection." In 2015 50th International Universities Power Engineering Conference (UPEC), 1-6.

Sedighizadeh M., Rezazadeh A., and Elkalashy N. 2010. "Approaches in High Impedance Fault Detection - A Chronological Review." AECE 10 (3): 11428. doi:10.4316/aece.2010.03019.

SMA Solar Technology AG. "Technical Information - Information on shortcircuit currents of SMA PV inverters.".

V. Gevorgian and E. Muljadi. "Wind Power Plant Short Circuit Current Contribution for Different Fault and Wind Turbine Topologies." NREL. http://www.nrel.gov/docs/fy11osti/49113.pdf.

Valentini, Massimo. 2008. "Fault current contribution from Wind Turbines with VSC to the grid." Master's Thesis at PED, Aalborg University.

Yazdani, Amirnaser, and Reza Iravani. 2010. Voltage-Sourced Converters in Power Systems: John Wiley \& Sons. 